\title{
Long-term prospective assessment of subconjunctival triamcinolone acetonide in addition to topical therapy in the management of chronic superficial keratitis
}

\author{
Florin BETEG ${ }^{1, a}$, Cristina Alexa LELESCU ${ }^{2, b \bowtie}$, Andrada Elena URDĂ-CÎMPEAN ${ }^{3, c}$, \\ Marian Aurel TAULESCU ${ }^{4, d}$, Cosmin MUREȘAN ${ }^{1, e}$
}

\begin{abstract}
${ }^{1}$ University of Agricultural Sciences and Veterinary Medicine, Faculty of Veterinary Medicine, Department of Surgery, ClujNapoca; ${ }^{2}$ Modis Competence Center, Modis Life Sciences Belgium, Cluj-Napoca; ${ }^{3}$ Iuliu Haţieganu University of Medicine and Pharmacy, Faculty of Medicine, Department of Medical Informatics and Biostatistics, Cluj-Napoca; ${ }^{4}$ University of Agricultural Sciences and Veterinary Medicine, Faculty of Veterinary Medicine, Department of Pathology, Cluj-Napoca, Romania. aORCID: 0000-0001-6916-188X; b ORCID: 0000-0002-6726-6028; ' ORCID: 0000-0001-7685-0085;
\end{abstract}

dORCID: 0000-0002-8987-6038; 'ORCID: 0000-0002-5064-6841.

Corresponding author: cristina.alexa.lelescu@gmail.com

Received date: 21.04.2020 - Accepted date: 21.07.2020

\begin{abstract}
Chronic superficial keratitis (CSK) is a progressive inflammatory disease in adult dogs, associated with corneal vascular proliferation, edema and melanic pigment deposition. In the absence of a curative therapy, the current approach for the management of CSK aims to control disease progression and eventually decrease the severity of corneal lesions. Subconjunctival injections of corticosteroids may be effective in severe cases, where topical therapy alone is inadequate. The aim of this study was to comprehensively evaluate the effectiveness of subconjunctival triamcinolone acetonide (TA) injection in addition to topical steroid treatment for the long-term management of CSK, in dogs unresponsive to conventional topical steroids. Treatment efficacy was assessed in 11 dogs with bilateral CSK by periodic evaluation of the cornea in terms of vascularization, edema and pigmentation for up to 120 weeks. Clinically significant reductions in corneal pigmentation $(\mathrm{P}<0.0001)$, vascularization $(\mathrm{P}<0.0001)$ and edema scores $(\mathrm{P}<0.0001)$ were achieved during therapy. The greatest reduction was exhibited by corneal edema, closely followed by vascularization. Corneal pigmentation was less responsive and complete regression has not been achieved in any of the dogs. Severely affected corneas exhibited greater improvements in terms of pigmentation, whereas moderately affected corneas showed a slight decrease. Corneal edema and vascularization were adequately controlled, whereas corneal pigmentation exhibited a lower decrease in severity and was more difficult to manage on a long-term basis. This study suggests that subconjunctival injection of TA in addition to topical steroids could represent an effective option for long-term management of CSK in dogs unresponsive to topical steroids alone.
\end{abstract}

Keywords: Chronic superficial keratitis, dogs, subconjunctival, triamcinolone acetonide.

\section{Introduction}

Chronic superficial keratitis (CSK), also known as pannus, is a chronic inflammatory disease of the cornea in adult dogs, characterized by local progressive vascular proliferation, edema, inflammatory mononuclear cell infiltration and melanic pigment deposition $(4,10)$. Etiopathogenesis of CSK is not fully understood, but generally, it is considered to be an autoimmune condition with a genetic component, commonly affecting German shepherds, Belgian shepherds and greyhounds $(16,18)$. In the early stage, a vascular conjunctival lesion is usually detected, followed by inflammatory cell infiltration of the corneal stroma, melanosis and corneal vascularization. The corneal changes progress gradually from the temporal limbal region towards the central area. As the disease progresses, opacification, edema and pigmentation may worsen and spread over the entire cornea $(10,18,21)$.

Currently, no curable treatment for CSK is known (18). Therefore, the primary treatment goal is to control the disease progression and eventually decrease the severity of corneal lesions (9). Classical approach of slightly or moderately affected cases involves the administration of long-term corticosteroid eye drops or ointments, alone or in addition to topical cyclosporine (18, 31). Application of tacrolimus and dimethyl sulfoxide drops resulted in decreased inflammatory activity and vascularization; still, gradual progression of pigmentation could not be ceased (4). Soft X-ray therapy (1), UV- 
blocking contact lenses (9), topical administration of pimecrolimus (24) and superficial keratectomy (18) were described as treatment options in order to control the disease progression and alleviate specific symptoms.

Subconjunctival injections of depot corticosteroids in addition to topical solutions (dexamethasone, prednisolone) are indicated in severe or non-responsive cases (21). Triamcinolone acetonide (TA) is a long-acting, moderate-potency synthetic corticosteroid with antiinflammatory, anti-permeability and anti-fibrotic properties $(2,19)$. TA has a rapid onset of action, prolonged and enhanced anti-inflammatory effect (3-6 weeks or more), decreased mineralocorticoid activity and significant glucocorticoid activity $(11,14)$. However, there is a lack of knowledge regarding the effectiveness and safety of long-term subconjunctival administration of TA in CSK.

In this context, our aim was to describe a long-term subconjunctival and topical steroid-antibiotic combination therapy for the management of CSK in dogs unresponsive to topical steroids alone. Furthermore, a prospective assessment of its clinical effectiveness in terms of corneal vascularization, edema and pigmentation, was performed over 120 weeks.

\section{Material and Methods}

Animals: A total number of 22 corneas from 11 canine patients aged 3-9 years, weighing between 8 to 45 $\mathrm{kg}$, with bilateral progressive corneal lesions of CSK of varying intensities (e.g. corneal vascularization, pigmentation, and edema) and with relevant cytological findings that were previously treated with conventional topical steroids and were unresponsive or relapsing, were enrolled in this study. Dogs were excluded if they had not been treated consistently due to poor owner compliance to treatment recommendations, or due to lack of follow-up. Severe corneal pigmentation that did not allow evaluation of vascularization was also considered as an exclusion criterion. The following patient's data were collected: breed, color, date of birth, gender, neuter status, country of origin and any concurrent diseases (if present). At the end of the study, all dogs remained under clinical observation.

Study design: The present prospective analytical study was conducted over a period of 120 weeks and was approved by the Bioethics Committee of the University of Agricultural Sciences and Veterinary Medicine ClujNapoca (No. 38/ 21.11.2016). The dogs were enrolled in the study consecutively as they arrived at the clinic for ophthalmologic evaluation and met the inclusion criteria. After informed consent was obtained from owners, the dogs were subjected to complete ophthalmologic examination in order to assess the severity of corneal lesions, including corneal edema, melanic pigmentation and vascularization, prior and during the treatment at 2, 4, 8, 12, 16, 20, 24, 48, 72, 96 and 120 weeks.

Ophthalmic examination and assessment of the corneal lesions: Each patient underwent direct $\left(\right.$ Heine ${ }^{\circledR}$ Beta 200) and indirect (Heine $^{\circledR}$ Omega 500) ophthalmoscopy, fluorescein staining (Fluoro Touch), Schirmer tear test (Tear Touch Blu) and intraocular pressure measurement (Tono-Pen ${ }^{\circledR}$, Reichert). The cornea was schematically divided into 24 sectors to assess corneal pigmentation $(1,12)$, and each sector was graded in terms of melanic pigmentation extent. Corneal vascularization and edema were quantified each, by using a specific four grade scale, as presented in Table 1.

Table 1. Grading of corneal alterations in dogs with CSK

\begin{tabular}{|c|c|c|}
\hline Corneal alterations & Grading system & Reference \\
\hline \multirow[b]{2}{*}{$\begin{array}{l}\text { Corneal melanic } \\
\text { pigmentation }\end{array}$} & (a) Schematic division of the cornea in 24 sectors & $(1,12)$ \\
\hline & 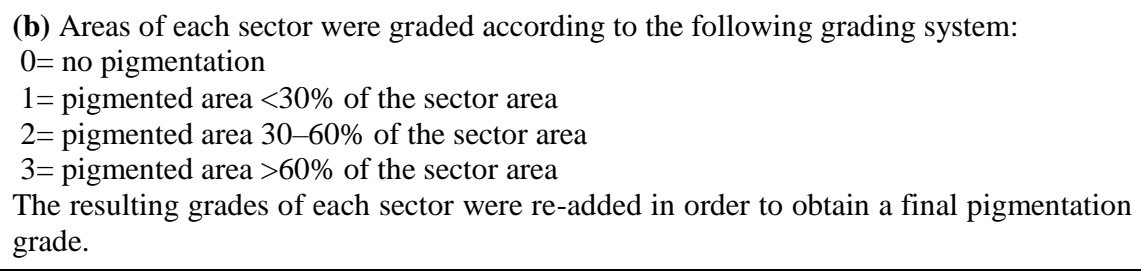 & $(3,4)$ \\
\hline $\begin{array}{c}\text { Corneal } \\
\text { neovascularization }\end{array}$ & $\begin{array}{l}0=\text { no vessels visible } \\
1=\text { mild superficial vascularization, thin vessels visible with magnification } \\
2=\text { profuse superficial vascularization } \\
3=\text { extensive vascularization } \text { with thick vessels present in all of the quadrants }\end{array}$ & (3) \\
\hline Corneal edema & $\begin{array}{l}0=\text { no signs } \\
0.5-1=\text { mild corneal haze } \\
2=\text { marked corneal opacity, but anterior chamber still visible } \\
3=\text { severe corneal opacity, anterior chamber not visible }\end{array}$ & (3) \\
\hline
\end{tabular}


Table 2. Administration protocol of topical and subconjunctival therapy

\begin{tabular}{ccccc}
\hline Dosing frequency & $\begin{array}{c}\text { Day 1- } \\
\text { week 4 }\end{array}$ & $\begin{array}{c}\text { Week } \\
\mathbf{4 - 8}\end{array}$ & $\begin{array}{c}\text { Week } \\
\mathbf{8}-\mathbf{2 4}\end{array}$ & $\begin{array}{c}\text { Week } \\
\mathbf{2 4 - 7 2}\end{array}$ \\
\hline $\begin{array}{c}\text { Neomycin sulfate-dexamethasone- } \\
\text { polymyxin B sulfate ophthalmic } \\
\text { suspension (1-2 drops) }\end{array}$ & 6-8 times/ day & 4 times/ day & 2 times/ day \\
$\begin{array}{c}\text { Triamcinolone acetonide injectable } \\
\text { suspension }(0.4 \mathrm{mg})\end{array}$ & - & 1 administration/ month & $\begin{array}{c}1 \text { administration every } 3 \\
\text { months }\end{array}$ \\
\hline
\end{tabular}

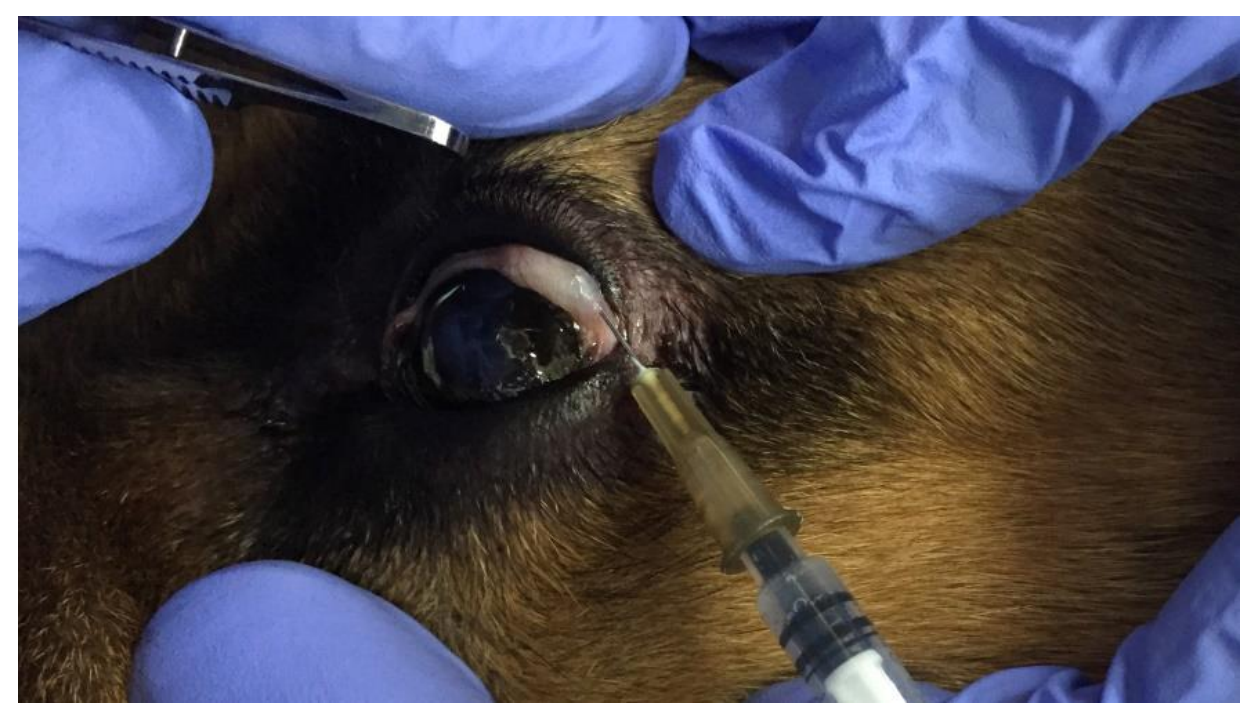

Figure 1. Site of subconjunctival injection

Treatment: Topical neomycin sulfate dexamethasone - polymyxin B sulfate ophthalmic suspension (Maxitrol ${ }^{\circledR}$, Alcon Couvreur, Belgium) was applied six to eight times a day, since day 1. Starting with the fourth week, $0.2 \%$ triamcinolone acetonide injectable suspension (Retardoesteroide ${ }^{\circledR}$, Laboratorios Calier, Spain) was administered subconjunctivally once-monthly. Topical administration of the steroid-antibiotic combination was decreased gradually since the $8^{\text {th }}$ week of treatment, to four times a day. Starting with the $24^{\text {th }}$ week, TA was injected subconjunctivally once every 3 months, simultaneously decreasing the frequency of administration of the ophthalmic suspension to twice a day. After 72 weeks of treatment, TA was administered every 6 months, and the steroid-antibiotic combination was applied topically one-two times a day for the rest of the treatment period (Table 2).

The subconjunctival injection was performed following topical anesthesia with $0.4 \%$ oxibuprocaine chlorhydrate (Benoxi ${ }^{\circledR}$, Unimed Pharma Ltd., Slovakia); in 4 patients, sedation was needed in order to complete the procedure. Using a fine needle $(25 \mathrm{G}), 0.4 \mathrm{mg}$ of TA injectable suspension $(2 \mathrm{mg} / \mathrm{ml})$, was administered beneath the bulbar conjunctiva, at the superotemporal quadrant (Figure 1). All dogs received the topical treatment and the subconjunctival injections in both eyes.
Statistical analysis: Quantitative data without normal distribution were described using the median (Q1Q3), where Q1-Q3 (interquartile range) stands for the range between $25^{\text {th }}$ percentile $(\mathrm{Q} 1)$ and $75^{\text {th }}$ percentile (Q3). The Friedman test (for repeated measures, used with post hoc tests) was applied to check if there was a significant difference between all non-normally distributed variables. A P-value equal to or lower than 0.05 was considered statistically significant. In case of a significant difference between all measurements, separate Wilcoxon signed-rank tests (using the Bonferroni correction) were run to compare the measurements from week 0 with each of the other weeks. A P-value equal to or lower than 0.0045 was considered statistically significant for the Wilcoxon signed-rank tests.

\section{Results}

A total of 11 dogs (3 females, 8 males) diagnosed with bilateral CSK were enrolled in this study, including 6 German shepherds (54.5\%), 2 German shepherd mix breeds (18.1\%), 2 Belgian shepherds (18.1\%) and one Pekingese $(9.09 \%)$. The mean age at diagnosis was $6.45 \pm$ 2.58 years. No other concurrent ophthalmic conditions were diagnosed in these dogs, besides CSK.

Cytologic examination of corneal scrapings revealed a moderate to large number of inflammatory cells, 
including lymphocytes and plasma cells, admixed with fibroblasts, endothelial cells, melanin-laden macrophages and hyperplastic epithelial cells.

Assessment of corneal lesions: The evolution of corneal lesion scores measured during the study is presented in Table 3. Comparing all measurements performed during treatment, a statistically significant difference in corneal pigmentation (Friedman test: $\mathrm{p}<0.0001$ ), neovascularization (Friedman test: $\mathrm{p}<0.0001$ ) and edema (Friedman test: $\mathrm{p}<0.0001$ ) scores was observed.

Corneal pigmentation assessment: The scores for corneal pigmentation decreased in time, from a median of 22.5 at week 0 to a median of 12.5 after 24 weeks of treatment (Table 3). A statistically significant reduction of corneal pigmentation scores was observed between the values measured at week 0 and those measured during the other weeks (Wilcoxon Signed Ranks Test: $\mathrm{P} \leq 0.0045$ ), (Table 4).

Corneal vascularization assessment: The scores for corneal vascularization decreased in time (Figure 2), from a median of 3 at week 0 to a median of 1 after 20 weeks of treatment (Table 3). There was no significant difference detected between the measured scores at week 0 and week 2 (Wilcoxon Signed Ranks Test: $\mathrm{P}=1$ ), nor between the scores obtained at week 0 and week 4 (Wilcoxon Signed Ranks Test: $\mathrm{P}=0.00815)$. However, a statistically significant reduction was detected after 8 weeks of treatment, compared to baseline (week 0) (Table 4).

Table 3. Descriptive statistics for ophthalmic examination measurements

\begin{tabular}{|c|c|c|c|}
\hline Week number & $\begin{array}{c}\text { Corneal pigmentation }(\mathrm{N}=22) \\
\text { Median }(\mathrm{Q} 1-\mathrm{Q3})\end{array}$ & $\begin{array}{c}\text { Corneal vascularization }(\mathrm{N}=22) \\
\text { Median }(\mathrm{Q} 1-\mathrm{Q3})\end{array}$ & $\begin{array}{l}\text { Corneal edema }(\mathrm{N}=22) \\
\text { Median }(\mathrm{Q} 1-\mathrm{Q3})\end{array}$ \\
\hline Week 0 & $22.50(16.75-37.25)$ & $3(2-3)$ & $2(2-3)$ \\
\hline Week 2 & $20.00(15.75-34.00)$ & $3(2-3)$ & $2(1.75-3)$ \\
\hline Week 4 & $19.00(14.00-31.00)$ & $2(1.75-3)$ & $1(1-2)$ \\
\hline Week 8 & $16.50(13.75-28.55)$ & $2(1-2)$ & $1(1-2)$ \\
\hline Week 12 & $14.50(11.75-27.00)$ & $2(1-2)$ & $1(0-2)$ \\
\hline Week 16 & $14.00(9.75-24.25)$ & $1.5(1-2)$ & $1(0-1)$ \\
\hline Week 20 & $14.50(9.00-21.25)$ & $1(1-2)$ & $0.5(0-1)$ \\
\hline Week 24 & $12.50(8.75-20.25)$ & $1(0-1.25)$ & $0(0-1)$ \\
\hline Week 48 & $11.00(8.00-20.5)$ & $1(0.75-2)$ & $0.5(0-1)$ \\
\hline Week 72 & $9.00(7.00-18.25)$ & $1(1-1.25)$ & $0.5(0-1)$ \\
\hline Week 96 & $9.00(5.75-16.50)$ & $1(0-1.25)$ & $0(0-1)$ \\
\hline Week 120 & $8.50(5.00-16.00)$ & $1(0-1.25)$ & $0(0-1)$ \\
\hline
\end{tabular}

Table 4. Comparison of corneal pigmentation, neovascularization and edema scores measured during treatment, with scores obtained at week 0 .

\begin{tabular}{|c|c|c|c|}
\hline $\begin{array}{l}\text { Comparison of } \\
\text { measurements }\end{array}$ & $\begin{array}{c}\text { Corneal pigmentation }(\mathrm{N}=22) \\
\text { Wilcoxon Signed Ranks Test: } \mathrm{P} \text { - } \\
\text { value }^{*}\end{array}$ & $\begin{array}{c}\text { Corneal neovascularization } \\
(\mathrm{N}=22) \\
\text { Wilcoxon Signed Ranks Test: } \\
\text { P-value }\end{array}$ & $\begin{array}{c}\begin{array}{c}\text { Corneal edema } \\
(\mathrm{N}=22)\end{array} \\
\text { Wilcoxon Signed Ranks } \\
\text { Test: } \text { P-value }\end{array}$ \\
\hline Week 0-Week 2 & 0.00005 & 1 & 0.1573 \\
\hline Week 0-Week 4 & 0.00003 & 0.00815 & 0.00001 \\
\hline Week 0-Week 8 & 0.00004 & 0.00018 & 0.00000 \\
\hline Week 0-Week 12 & 0.00004 & 0.00002 & 0.00001 \\
\hline Week 0-Week 16 & 0.00004 & 0.00002 & 0.00002 \\
\hline Week 0-Week 20 & 0.00004 & 0.00002 & 0.00002 \\
\hline Week 0-Week 24 & 0.00004 & 0.00002 & 0.00002 \\
\hline Week 0-Week 48 & 0.00004 & 0.00002 & 0.00004 \\
\hline Week 0-Week 72 & 0.00004 & 0.00002 & 0.00003 \\
\hline Week 0-Week 96 & 0.00004 & 0.00002 & 0.00002 \\
\hline Week 0-Week 120 & 0.00004 & 0.00002 & 0.00002 \\
\hline
\end{tabular}

\footnotetext{
"Significance level: $\mathrm{P} \leq 0.0045$
} 


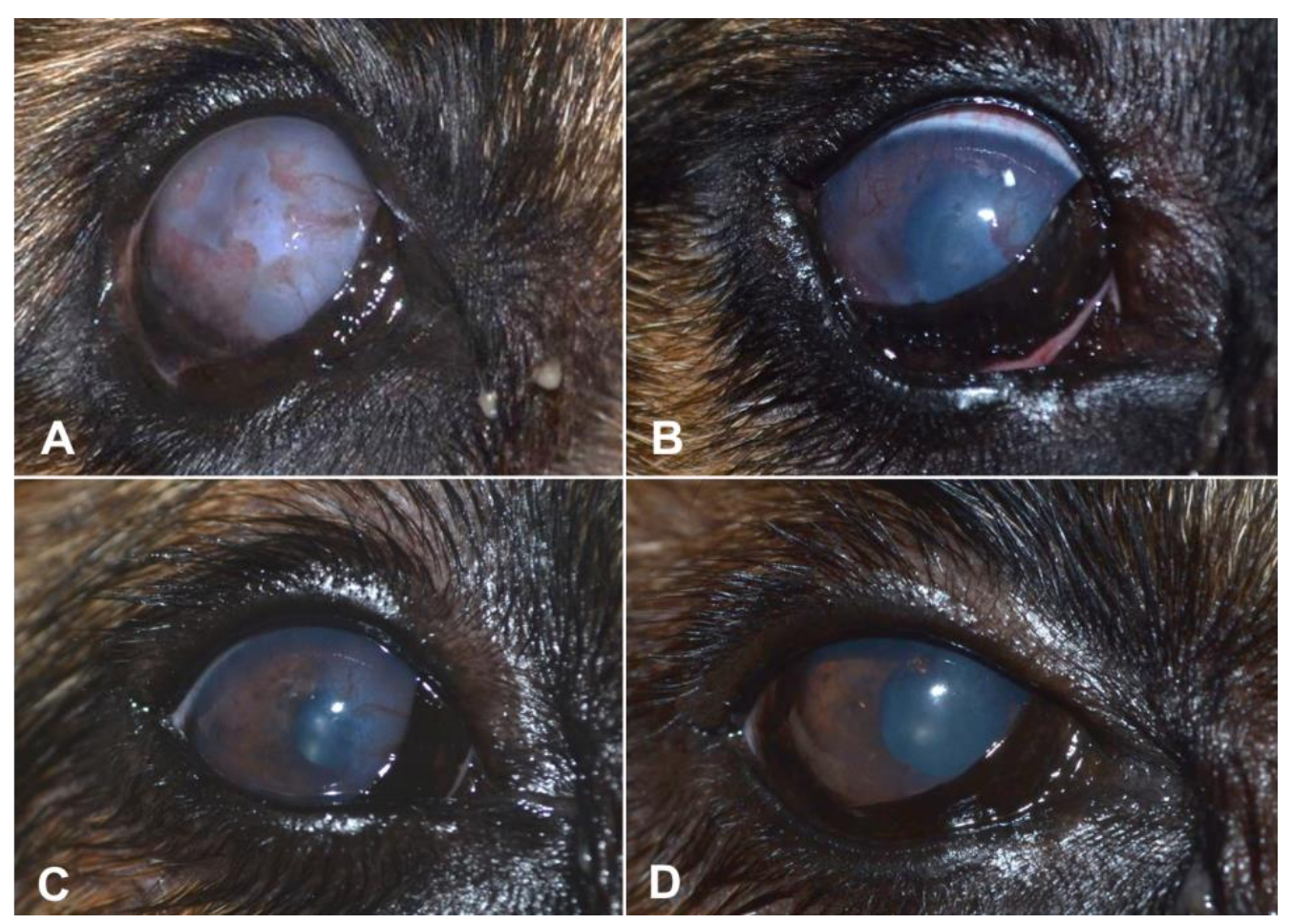

Figure 2. Evolution of corneal lesions during polytherapy (German Shepherd male, age at diagnosis: 4 years). A. 100\% of the cornea is affected by severe edema, fibrovascular proliferation and pigmentation (at the lower temporal quadrant) before initiating the polytherapy (week 0). B. 6 weeks after starting the polytherapy, the corneal lesions are markedly drecreased, allowing visualization of the iris and pupil C. At week 20, edema and fibrovascular proliferation are significantly regressed, particularly in the temporal half of the cornea D. At week 120, regressed (ghost) vessels and partially regressed vessels with slight edema are still present at the nasal half of the cornea. Pigmentation is visible at the lower temporal quadrant.

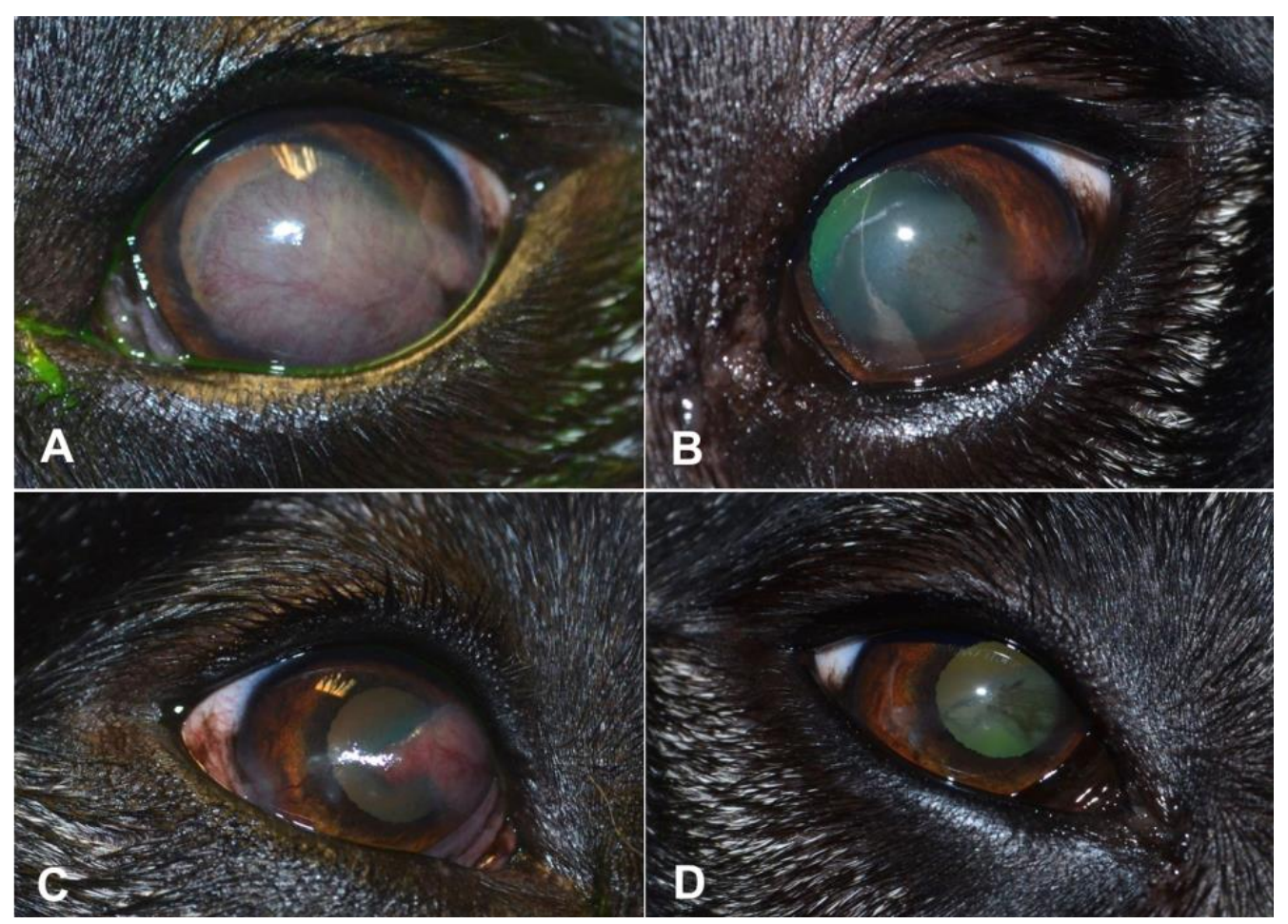

Figure 3. Evolution of corneal lesions during polytherapy (Mix breed female, age at diagnosis: 6 years). A. Left eye, week 0: more than $50 \%$ of the cornea is affected by severe fibrovascular proliferation and pigmentation (at the lower temporal quadrant) before initiating the polytherapy B. Left eye, week 72: the fibrovascular proliferation is markedly attenuated, allowing corneal transparency; mild vascularization with pigmentation are still present in the lower temporal quadrant $\mathbf{C}$. Right eye, week 0 : less than $50 \%$ of the cornea is affected by fibrovascular proliferation extending centrally from the nasal angle; pigmentation is present in the lower temporal quadrant D. Right eye, week 72: significant attenuation of the fibrovascular tissue, allowing corneal transparency. 
Corneal edema assessment: The score for corneal edema decreased in time, from a median of 2 at week 0 to a median of 0.5 after 20 weeks of treatment. Subsequently, the mean score increased at week 48 and 72 and then decreased again, reaching a median value of 0 at week 120 (Table 3). There were no significant differences between the measurements at week 0 and week 2 in terms of corneal edema scores (Wilcoxon Signed Ranks Test: $\mathrm{P}=0.1573$ ). However, there was a statistically significant reduction of the scores after 4 weeks of treatment, compared to week 0 (Table 4).

Epithelial and stromal damage of the cornea led to the development of subsequent corneal scarring in patients with severe lesions. However, all eyes remained visual during therapy and no signs of a decrease in visual acuity were observed.

Side effects: There were no major side effects of using this therapeutic protocol that required its discontinuation. Mild to moderate discomfort, accompanied by blepharospasm, irritation and scratching of the eyeball were noted in 3 dogs, mainly after administration of the ophthalmic drops. These signs ceased after using an Elizabethan collar until the dogs were accustomed to the procedure.

\section{Discussion and Conclusion}

The results obtained in this study provide an accurate long-term assessment of an ophthalmic combination therapy, consisting of TA subconjunctival injections in addition to topical steroid-antibiotic administration, in dogs with CSK, by using a scoring system for each specific corneal lesion. To the author's knowledge, this is the first long-term follow-up study of such a polytherapy in the management of canine pannus. Because CSK is a progressive disease that requires life-long therapy (18), we strongly believe that long-term assessment of various treatment options provides a valuable contribution to the management plan of this condition.

Previous studies $(5,13,17,22)$ have mentioned the potential benefits of subconjunctival corticosteroid injections, including betamethasone and methylprednisolone acetate in the treatment of CSK. However, none of these researches performed a long-term follow-up of subconjunctival TA administration as part of a combination therapy. Although intravitreal TA has been evaluated in dogs in terms of safety and efficacy (23), much more is known about the subconjunctival administration of TA in human ophthalmology, particularly in the treatment of endothelial corneal allograft rejection (6) and non-necrotizing anterior scleritis (27). Therefore, difficulties were encountered in comparing the data obtained in this study with other previous studies carried out in a similar context; in spite of this, we compared our findings with studies that used a similar assessment model of corneal lesions treated with various adjuvant therapies.

Data periodically collected during this study on the independent evolution of CSK typical clinical signs showed a distinctive efficacy of the polytherapy on each type of lesion (pigmentation, neovascularization, edema). The main emerging result is that the scores measured in each type of lesion at 120 weeks of treatment were significantly decreased, compared to those obtained initially. Of the assessed lesions, corneal edema exhibited the greatest reduction of severity. In addition, total resolution of the edema was detected in 13 out of 22 corneas at the end of the study period. Immune-mediated keratitis may be associated with vascular damage of the corneal endothelium, leading to the absorption of aqueous humour and early-onset of edema (18). Even though the recurrence of edema was noticed during therapy, an overall decrease occurred in all of the cases. Adjunctive therapies such as cryotherapy and UV-blocking contact lenses showed a significant drawback from this point of view, by causing additional corneal edema due to hypoxic stress or epithelial injury $(3,9)$.

Any kind of corneal injury that causes inflammation may induce angiogenesis (20). Corneal vascularization was proved to be the second most responsive lesion to polytherapy. The initial average score of corneal vascularization decreased from 3 to 1 at 120 weeks after starting the polytherapy. Moreover, a considerable number of 6 out of 22 corneas showed a total resolution in terms of angiogenesis. Previous studies reported no effects of UV-blocking lens on vascularization (9), whilst topical application of pimecrolimus proved remarkable efficacy in half of the animals (24). Both polytherapy and topical pimecrolimus caused a similar effect on vascularization in the first 2 weeks of treatment, leading to a significant reduction in its severity. However, complete regression occurred after 11 weeks of topical pimecrolimus administration, while the present polytherapy indicated a similar effect after 16 weeks, in only one cornea. A significant decrease in corneal vascularization was also achieved with tacrolimus and dimethyl sulfoxide (DMSO) ophthalmic drops (4), but the long-term clinical evolution of vascular lesions is still unknown. Soft X-ray therapy caused a similar decrease in vascularization, that was maintained for 24 weeks after completion of the procedure in most eyes (1). Despite this, no data on the evolution of vascular lesions beyond this period is yet available.

The average corneal pigmentation scores obtained in periodical evaluations suggest a significant decrease of almost $50 \%$ after 120 weeks of treatment. Unfortunately, 
complete resolution of this lesion has not been achieved in any of the treated corneas and relapses occurred during the treatment. The most prominent reduction in corneal pigmentation occurred in severely affected corneas, whereas mild to moderately affected corneas exhibited a slower and less pronounced improvement. This is in good agreement with the results obtained after topical administration of pimecrolimus (24), where regression of pigmentation in the least affected cornea took 24 weeks. While pigmentation increased in eyes wearing UVblocking contact lenses (9), a very rapid improvement was observed 5 days following cryotherapy. Despite this rapid effect, after 30 days, recurrence of pigmentation was detected. Administration of DMSO and tacrolimus resulted in a reduction of pigmentation in 14 out of 32 corneas, over a period of 5 weeks (4). It is generally considered that corneal pigmentation is more difficult to manage for the long-term than other typical corneal changes, such as neoangiogenesis and granulation tissue proliferation $(18,28)$.

Various injectable preparations of corticosteroids are available, including betamethasone, dexamethasone, methylprednisolone acetate and triamcinolone (acetonide and diacetate). Subconjunctival depot injection of TA allows a slow release from the injection site, thus ensuring a prolonged duration of action which can last up to 3-6 weeks or more $(9,14,15)$. Even if it was long believed that subconjunctival injections may have the potential to cause scleral thinning and even globe perforation $(8,30)$, subsequent studies performed on a representative number of patients indicated the opposite $(7,29)$. However, these studies have been conducted in human patients and there are no extensive reports on the safety of long-term subconjunctival administration in dogs, although it is a convenient and easy-to-perform therapeutic procedure in veterinary practice, as compared to certain therapeutic alternatives described above.

Suggested doses for subconjunctival injection in dogs are still contradictory. They may vary between 4-12 mg according to some authors (26), whereas others contraindicate intralesional administration of more than $0.6 \mathrm{mg}$ at one site (25). Even if short-term administration of high doses does not appear to cause toxicity, long-term treatment with TA can lead to serious adverse effects (25). Since the present therapy included concomitant daily topical administration of dexamethasone, we considered using lower doses of subconjunctival TA than those typically recommended for this procedure. Furthermore, we aimed to gradually reduce the frequency of administration of the topical therapy, from six-eight times a day to only twice a day after 24 weeks, concomitantly increasing the intervals between subconjunctival administrations. This resulted in an inhibition of corneal pigmentation regression in most cases and slight recurrence in 10 out of 22 corneas. No significant effects on the other corneal scores were observed.

Our study has several limitations. First, it would have been beneficial to include a distinct control group, treated only with topical steroids. On the other hand, the study was performed on client-owned dogs diagnosed with a progressive corneal disease, that were previously treated with conventional topical therapy alone and were either unresponsive to treatment or had clinical signs of relapse after a period of time. Therefore, we consider that meaningful conclusions could be drawn despite this limitation. Secondly, the authors admit the relatively small number of dogs included in the study. Still, CSK is not frequently encountered in temperate climate countries and, moreover, the chosen inclusion criteria led to a significant reduction in the number of dogs enrolled.

The results of this study suggest that subconjunctival injection of triamcinolone acetonide in addition to topical steroid-antibiotic therapy could represent an effective option for the long-term management of CSK in dogs unresponsive to topical steroids. Among the corneal lesions evaluated, corneal edema and vascularization showed a superior response to treatment, while pigmentation was more difficult to manage on a long-term basis.

\section{Financial Support}

This research received no grant from any funding agency/sector.

\section{Ethical Statement}

This study was approved by Bioethics Committee of the University of Agricultural Sciences and Veterinary Medicine Cluj-Napoca (No. 38/ 21.11.2016).

\section{Conflict of Interest}

The authors declared that there is no conflict of interest.

\section{References}

1. Allgoever I, Hoecht S (2010): Radiotherapy for canine chronic superficial keratitis using soft $X$ - rays. Vet Ophthalmol, 13, 20-25.

2. Athanasiadis I, de Wit D, Patel AK, et al (2012): Subconjunctival injection of triamcinolone acetonide in the management of corneal graft rejection and new vessels. $\mathbf{J}$ Clin Pharmacol, 52, 607-612.

3. Azoulay T (2013): Adjunctive cryotherapy for pigmentary keratitis in dogs: a study of 16 corneas. Vet Ophthalmol, 17, 241-249.

4. Balicki I (2012): Clinical study on the application of tacrolimus and DMSO in the treatment of chronic superficial keratitis in dogs. Polish J Vet Sci, 15, 667-676.

5. Bedford PGC (1972): The treatment of keratitis and corneal ulceration in the dog. Vet Ann, 13. 
6. Costa DC, de Castro RS, Kara-Jose N (2009): Casecontrol study of subconjunctival triamcinolone acetonide injection vs intravenous methylprednisolone pulse in the treatment of endothelial corneal allograft rejection. Eye, 23, 708-714.

7. Croasdale CR, Brightbill MD (1999): Subconjunctival Corticosteroid Injections for Nonnecrotizing Anterior Scleritis. Arch Ophthalmol, 117, 978-979.

8. de la Maza MS, Jabbur NS, Foster CS (1993): An analysis of therapeutic decision for scleritis. Ophthalmology, 100, 1372-1376.

9. Denk N, Fritsche J, Reese S (2011): The effect of $U V$ blocking contact lenses as a therapy for canince chronic superficial keratitis. Vet Ophthalmol, 14, 186-194.

10. Esson DW (2015): Clinical atlas of canine and feline ophthalmic disease. JohnWiley \& Sons Inc, Ames, Iowa.

11. Grossmann C, Scholz T, Rochel M, et al (2004): Transactivation via the human glucocorticoid and mineralocorticoid receptor by therapeutically used steroids in CV-1 cells: a comparison of their glucocorticoid and mineralocorticoid properties. Eur J Endocrinol, 151, 397 406.

12. Grüning G, Allgoewer I, Höcht S, et al (2001): Zur strahlentherapie der keratitis superficialis chronica mit strontium 90. Kleintierpraxis, 46.

13. Hallstrom M (1970): Synspunkter ph behandling av keratitis chronica superficialis. Svensk Veterinartidning, 22.

14. Hardman JG, Limbird LE, Gilman AG (2001): Goodman \& Gilman's The Pharmacological Basis of Therapeutics. McGraw Hill, New York.

15. Jermak CM, Dellacroce JT, Heffez J, et al (2007): Triamcinolone acetonide in ocular therapeutics. Surv Ophthalmol, 52, 503-522.

16. Jokinen P, Rusanen EM, Kennedy LJ, et al (2011): $M H C$ class II risk haplotype associated with canine chronic superficial keratitis in German Shepherd dogs. Vet Immunol Immunopathol, 140, 37-41.

17. Krahenmann A (1972): Zur therapie der keratitis superficialis chronica (uberreiter) des deutschen schaferhundes. Ophthalmologica, 165.

18. Ledbetter EC, Gilger BC (2013): Diseases and Surgery of the Canine Cornea and Sclera. 976-1050. In: KN Gelatt
(Ed), Veterinary Ophthalmology. Wiley-Blackwell, Ames, Iowa.

19. Lewis G, Campbell W, Johnson A (1986): Inhibition of prostaglandin synthesis by glucocorticoids in human endothelial cells. Endocrinology, 119, 62-69.

20. Maddula S, Davis DK, Maddula S, et al (2011): Horizons in therapy for corneal angiogenesis. Ophthalmology, 118, 591-599.

21. Maggs DJ (2008): Cornea and Sclera. 175-202. In: DJ Maggs, P Miller, R Ofri (Eds), Slatter's Fundamentals of Veterinary Ophthalmology. Elsevier Saunders, Philadelphia.

22. Magrane WG (1971): Canine Ophthalmology. Lea \& Febiger, Philadelphia.

23. Molleda JM, Tardón RH, Gallardo JM, et al (2008): The ocular effects of intravitreal triamcinolone acetonide in dogs. Vet J, 176, 326-332.

24. Nell B, Walde I, Billich A, et al (2005): The effect of topical pimecrolimus on keratoconjunctivitis sicca and chronic superficial keratitis in dogs: results from an exploratory study. Vet Ophthalmol, 8, 39-46.

25. Plumb DC, Pharm D (2008): Plumb's Veterinary Drug Handbook. Blackwell Publishing, Ames, Iowa.

26. Rankin A (2013): Clinical Pharmacology and Therapeutics, Anti-Inflammatory and Immunosuppressant Drugs. 407423. In: KN Gelatt (Ed), Veterinary Ophthalmology. WileyBlackwell, Ames, Iowa.

27. Roufas A, Jalaludin B, Gaskin C, et al (2010): Subconjunctival triamcinolone treatment for nonnecrotising anterior scleritis. Br J Ophthalmol, 94, 743-747.

28. Sandmeyer LS, Bauer BS, Grahn BH (2017): Diagnostic Ophthalmology. Can Vet J, 58, 91-93.

29. Tu EY, Culbertson WW, Pflugfelder SC, et al (1995): Therapy of nonnecrotizing anterior scleritis with subconjunctival corticosteroid injection. Ophthalmology, 102, 718-724.

30. Watson PG (1974): Treatment of scleritis and episcleritis. Trans Ophthalmol Soc UK, 94, 773.

31. Williams D, Hoey A, Smitherman P (1995): Comparison of topical cyclosporin and dexamethasone for the treatment of chronic superficial keratitis in dogs. Vet Rec, 137, 635639. 